\section{OPEN ACCESS}

Edited by: Oswin Grollmuss, Université Paris-Sud, France

Reviewed by:

Gianluca Trocchio,

Giannina Gaslini Institute (IRCCS), Italy

Pierluigi Festa,

Gabriele Monasterio Tuscany

Foundation (CNR), Italy

*Correspondence:

Christian Apitz

capitz@aol.com

these authors have contributed equally to this work and share first authorship

Specialty section: This article was submitted to

Pediatric Cardiology, a section of the journal

Frontiers in Pediatrics

Received: 10 December 2019 Accepted: 25 March 2020

Published: 30 April 2020

Citation:

Siaplaouras J, Niessner C, Helm PC, Jahn A, Flemming M, Urschitz MS, Sticker E, Abdul-Khaliq H, Bauer UM and Apitz C (2020) Physical Activity

Among Children With Congenital Heart Defects in Germany: A Nationwide Survey.

Front. Pediatr. 8:170

doi: 10.3389/fped.2020.00170

\title{
Physical Activity Among Children With Congenital Heart Defects in Germany: A Nationwide Survey
}

\begin{abstract}
Jannos Siaplaouras ${ }^{1 \dagger}$ Claudia Niessner ${ }^{2 \dagger}$, Paul C. Helm ${ }^{3}$, Annika Jahn ${ }^{1}$, Markus Flemming ${ }^{4}$, Michael S. Urschitz ${ }^{5}$, Elisabeth Sticker ${ }^{6}$, Hashim Abdul-Khaliq ${ }^{7}$, Ulrike M. Bauer ${ }^{3}$ and Christian Apitz ${ }^{1 *}$ on behalf of the German Competence Network for Congenital Heart Defects Investigators

${ }^{1}$ Division of Pediatric Cardiology, Children's Hospital, University of UIm, UIm, Germany, ${ }^{2}$ Institute of Sports and Sports Science, Institute of Technology, Karlsruhe, Germany, ${ }^{3}$ National Register for Congenital Heart Defects, DZHK (German Centre for Cardiovascular Research), Berlin, Germany, ${ }^{4}$ Coaching Competence Cooperation, Berlin, Germany, ${ }^{5}$ Abteilung für Pädiatrische Epidemiologie, Institut für Medizinische Biometrie, Epidemiologie und Informatik, Universitätsmedizin der Johannes Gutenberg-Universität Mainz, Mainz, Germany, ${ }^{6}$ Department Psychology, Faculty of Human Sciences, University of Cologne, Cologne, Germany, ${ }^{7}$ Klinik für Pädiatrische Kardiologie, Universitätsklinikum des Saarlandes, Homburg, Germany
\end{abstract}

Objective: In children with congenital heart defects (CHD), a sedentary lifestyle should be avoided and usually WHO recommendations on physical activity (PA) are supposed to be followed. In order to obtain representative data of the actual amount of PA (and potential influencing factors) in children with CHD we performed a nationwide online survey.

Methods: All patients aged 6-17 years registered in the German National Register for CHD were contacted by email and asked to participate in the survey using the comprehensive questionnaire of the "Motorik-Modul" from the German Health Interview and Examination Survey for Children and Adolescents (KiGGS), thus allowing the comparison with a representative age-matched subset of 3.385 participants of the KiGGS study. The questionnaire for CHD-patients was amended by specific questions regarding medical care, sports recommendations and PA restrictions.

Results: Complete datasets of 1.198 patients (mean age of $11.6 \pm 3.1$ years) were available for evaluation. Compared to the reference group, $\mathrm{CHD}$ patients significantly less frequently reached the $\mathrm{WHO}$ recommended level of 60 min of daily PA (8.8 vs. $12 \% ; p$ $<0.001)$. Enjoyment in sports was almost equally distributed across $\mathrm{CHD}$ and reference groups, and strongly correlated with the level of PA $(r=0.41 ; p<0.001)$. Remarkably, $49.2 \%$ of children with complex CHD, $31.7 \%$ with moderate, and even $13.1 \%$ with simple $\mathrm{CHD}$ were advised by their physician to restrict PA.

Conclusions: According to this nationwide survey, PA is markedly reduced in children with $\mathrm{CHD}$. An important reason for this might be an unexpected high rate of physician-recommended restrictions on levels of PA.

Keywords: congenital heart defect (CHD), physical activities and sports, survey, pediatric cardiology, exercise limitation 


\section{INTRODUCTION}

Occurring at a rate of $1.1 \%$ out of all newborns, congenital heart defects (CHD) are the most frequent congenital malformation diagnosed in children (1). Due to recent improvements in surgical and interventional techniques as well as perioperative intensive care management, survival of children with CHD has markedly improved during the last decades, resulting in a growing number to survive to adulthood (2). As CHD patients get older, their cardiac health can additionally be affected by acquired cardiovascular risk factors (i.e., arterial hypertension, obesity, diabetes) commonly seen in the general population, thus increasing the risk of metabolic disease, stroke and coronary artery disease $(3,4)$. In fact, a recent study has suggested that myocardial infarction will become the leading cause of death in CHD patients with simple cardiac defects (5). It is known, that development of arteriosclerotic and metabolic disease manifesting in adulthood usually starts already in early childhood. Childhood obesity and sedentary lifestyle are known to represent major contributing factors (5). This highlights the need for primary prevention, hence lifestyle interventions are required to promote physical activity (PA) of pediatric CHD-patients $(6,7)$. Not to mention, that PA is indispensable for physical, emotional, and psychosocial development of children (8-10).

Thus, there is emerging consensus that children and adolescents with CHD should be encouraged to adopt a physically active lifestyle, and consequently, current sports recommendations for the majority of patients with simple and moderate CHD include participation in competitive sports, leisure sports and PA unrestricted following the World Health Organisation (WHO) recommendations for healthy children, i.e., daily participation of $60 \mathrm{~min}$ in moderate-to-vigorous $\mathrm{PA}$ that is developmentally appropriate and enjoyable (11). Complex CHD often requires more specific recommendations yet still with the aim to enable a physically active lifestyle.

Whether these recommendations on PA in children with CHD are adequately considered and generally implemented remained unanswered to this day. Previous studies investigating PA in children with CHD showed rather conflicting results. While some authors reported of reduced PA, especially in complex $\mathrm{CHD}$, others revealed similar PA-levels compared to healthy controls (12-20). Discrepancies of results might be explained by differences in study designs and PA assessment tools, and furthermore, common to all of these studies are relatively small patient numbers included.

Therefore, we conducted a nationwide survey in collaboration with the German National Register for CHD (NRCHD) in order (I) to obtain representative data regarding the real world situation of the amount of PA and sports participation and its impact on physical self-perception in children with CHD living in

\footnotetext{
Abbreviations: CHD, congenital heart defects; KiGGS, German Health Interview and Examination Survey for Children and Adolescents; MoMo, Motorik-Modul; NRCHD, National Register for congenital heart defects; PA, Physical Activity; PACES, Physical Activity Enjoyment Scale for children and adolescents; PAQ, Physical Activity Questionnaire; WHO, World Health Organization.
}

Germany, (II) to detect differences compared to children without CHD using an appropriate reference cohort, and (III) to study factors potentially influencing PA and sports participation in CHD patients.

\section{MATERIALS AND METHODS}

\section{Study Design}

This cross-sectional online survey was conducted from January to March 2018. Participants were recruited via the patient database of the NRCHD, the largest European registry for CHD patients (21). For patient recruitment, the database was searched for patients aged between 6 and 17 years at the time of the survey. Respective individuals and their parents were contacted and invited to take part in the survey via email. Ethical approval was obtained by the institutional ethical committee. The study protocol conforms to the ethical guidelines of the 1975 Declaration of Helsinki.

\section{Survey Instruments}

PA and sports participation were assessed using the validated comprehensive questionnaire of the "Motorik-Modul" (MoMo) from the German Health Interview and Examination Survey for Children and Adolescents (KiGGS), thus allowing the comparison of obtained data with a representative age-matched subset of 3.385 same-aged participants of the MoMo wave 2 study (2015-2017) (22). Design and results of the MoMo Baseline and Longitudinal Study and details on the structure and content of the MoMo Physical Activity Questionnaire (MoMo-PAQ) have been published previously (22-25). Briefly, it consists of 28 items regarding frequency, duration and intensity of PA to capture habitual PA in different domains (PA in sports clubs, leisure time PA outside of sports clubs, extra-curricular PA, outdoor play, active commuting to school). Furthermore, the MoMoPAQ consists of 36 items, which assess physical self-description based on the German version of the Physical Self-Description Questionnaire with answer categories to a 4-point Likert Scale (26). These 36 items represent the basic functions of physical performance: strength, endurance, speed, skills, coordination, and flexibility.

In addition, MoMo-PAQ included the German version of the Physical Activity Enjoyment Scale for children and adolescents (PACES) (27). The scale consists of 16 items (nine positive poled items, seven negative poled items) with answer categories to a 5-point Likert Scale.

The questionnaire for CHD-patients was amended by eight specific questions capturing the medical background of sports recommendations, sports restrictions and access to sports.

\section{Statistical Analysis}

Values of continuous variables are reported as mean \pm standard deviation. The Pearson's chi-square test was used for group comparisons including nominal data (e.g., gender and age). In order to assess the impact of potential contributing factors on $\mathrm{PA}$, analysis of variance and analysis of covariance, Pearson's correlation as well as multiple and linear regression analysis was used, as appropriate. IBM SPSS statistics version 25.0 (IBM 
TABLE 1 | Classification of CHD severity according to Warnes et al. (28).

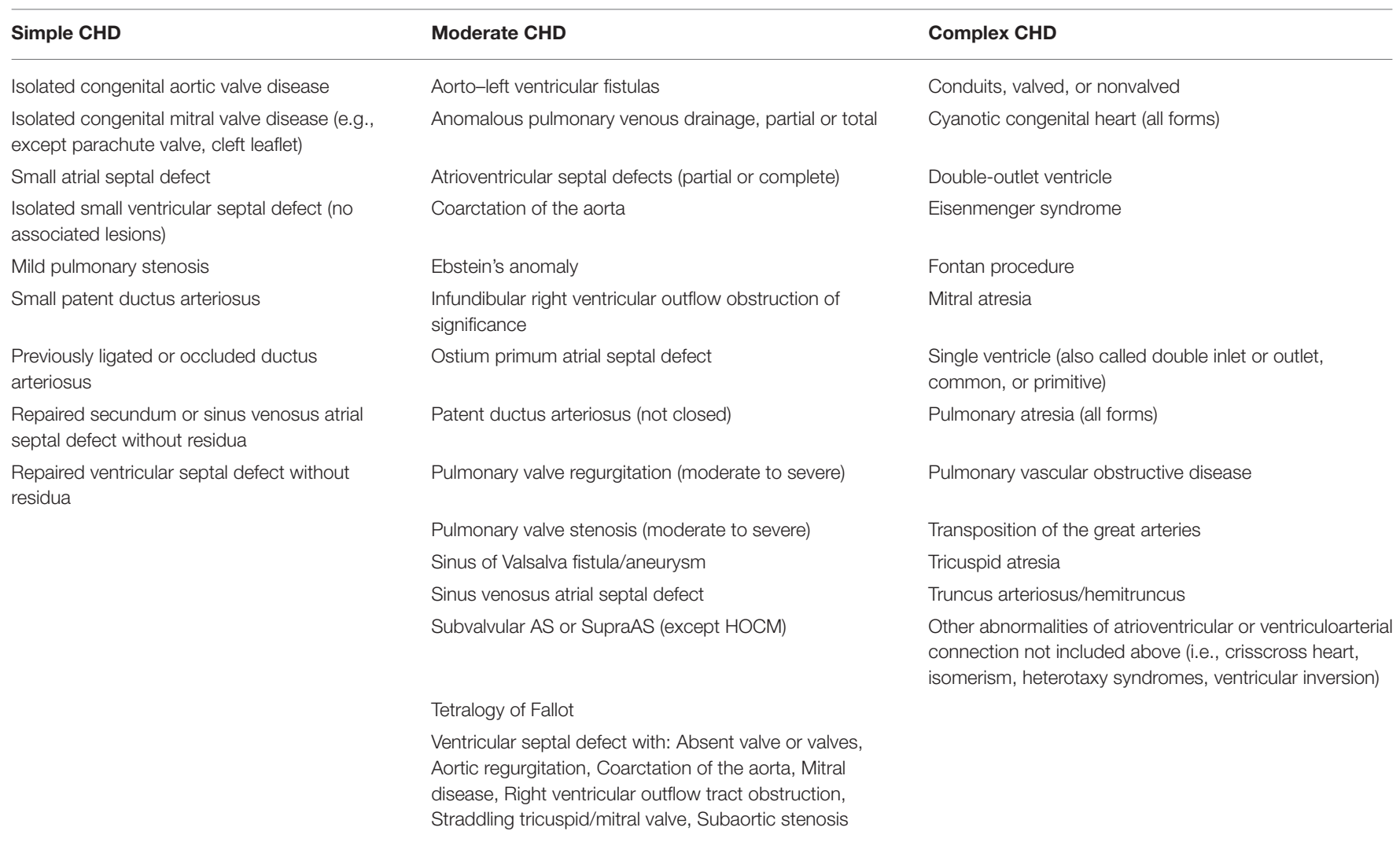

CHDs were divided into simple, moderate and complex CHD according to the classification system by Warnes et al. (28). It is possible to be classified from a lighter group to a heavier group due to interventions and/or operations. Conversely, this is not possible. Therefore, this table shows only a rough schema of the severity classification. Taking all factors into account would be too extensive.

Inc., Armonk, NY, USA) was used for statistical analyses. A significance level of $p \leq 0.05$ was applied.

\section{RESULTS}

\section{Patient Characteristics}

Of 21.354 eligible patients, invitation was successfully delivered to 14.496 patients. 1.718 patients decided to participate in the study. Only complete datasets were considered for evaluation and were available from $1.198 \mathrm{CHD}$ patients with a mean age of $11.6 \pm 3.1$ years. Of those $53.8 \%$ were male, and $46.2 \%$ female. The study participants were allocated into simple, moderate and complex CHD classification according to Warnes et al. (28) (Table 1). Thus, 411 (34.3\%) were classified as simple CHD, 423 (35.3\%) moderate, and 364 (30.4\%) as complex CHD. Included patients had untreated $\mathrm{CHD}$ in $49.3 \%, 1-3$ operations/interventions in $30.2 \%$, and more than three operations/interventions in $20.5 \%$. Genetic syndromes and chromosomal disorders were present in 70 patients $(5.8 \%)$, most frequently trisomy 21 in 37 patients $(3.1 \%)$ and Di-GeorgeSyndrome in 15 patients (1.3\%). Of all patients, $57.2 \%$ stated to live in an urban or suburban environment, whereas $42.8 \%$ live in rural areas. Patient characteristics of the study group did not significantly differ to the entire cohort of eligible patients.

\section{Physical and Sports Activity}

Compared to MoMo participants, CHD patients reached significantly less frequently the WHO recommended level of 60 min of daily PA (8.8 vs. $12 \%$; $p<0.001$ ), simple CHD 9.2\%, moderate $9.2 \%$, and complex CHD $8.0 \%$. Children with $\mathrm{CHD}$ were 0.62 days per week less active than those of the reference group $(p<0.001)$ (Figure 1).

Participation in sports clubs was significantly reduced in children with complex CHD compared to MoMo participants (53.6 vs. $67.6 \%$; $p<0.001$ ), whereas patients with simple and moderate CHD showed similar frequent participation as the reference group (74.9 and $66.2 \%$, respectively). $61.4 \%$ of children with simple, $56.8 \%$ with moderate and $47.7 \%$ with complex CHD stated to participate even in competitive sports, compared to $53.1 \%$ of the reference group.

\section{Enjoyment in Sports}

Enjoyment in sports was almost equally distributed across CHD groups and MoMo participants. Using the positive dimension of the PACES Scale ranging from 9 to 45 points we found 35.9 points for patients with simple CHD, 34.6 points for moderate and 33.2 points for patients with complex CHD, compared to 35.2 points for the reference group. Enjoyment in sports correlated with the level of PA $(r=0.41 ; p<0.001)$. 


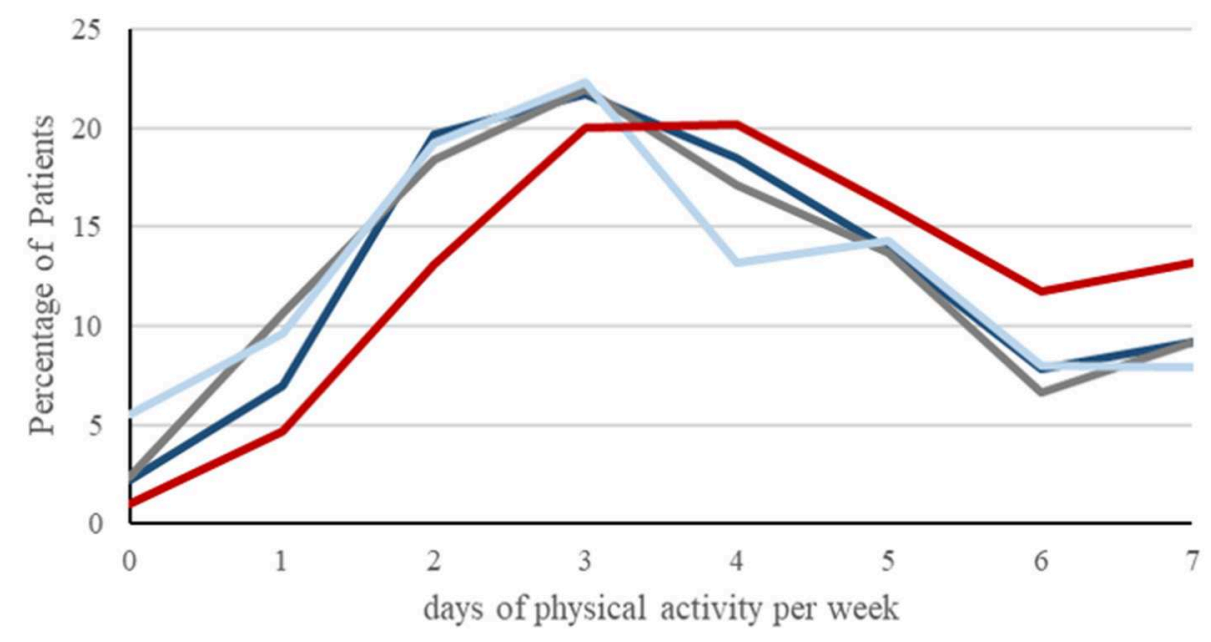

$\longrightarrow$ simple $\mathrm{CHD} \longrightarrow$ moderate $\mathrm{CHD} \longrightarrow$ complex $\mathrm{CHD} \longrightarrow$ reference group

FIGURE 1 | Graphical presentation of days of physical activity per week, achieved by patients with simple $(n=411)$, moderate $(n=423)$ and complex CHD $(n=364)$ compared to the reference group $(n=3.338)$ in percent. Children with CHD were 0.62 days per week less active than those of the reference group $(p<0.001)$.

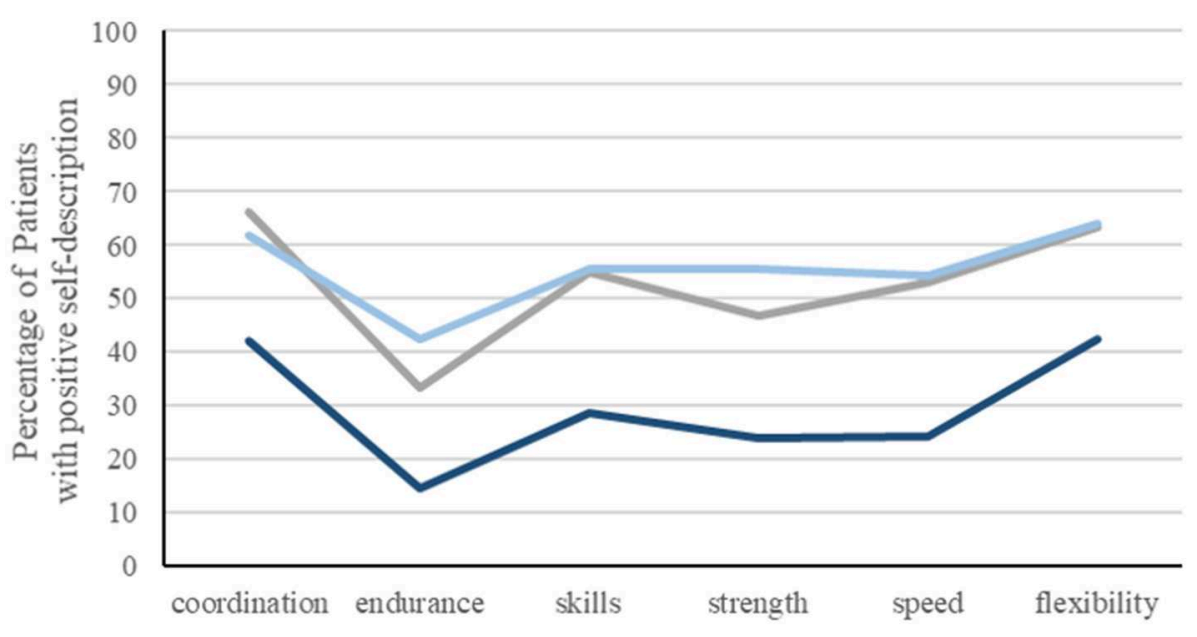

$0-2$ days of physical activity per week
$3-4$ days of physical activity per week
$5-7$ days of physical activity per week

FIGURE 2 | Relationship between positive physical self-description of basic functions of physical performance (strength, endurance, speed, skills, coordination, flexibility) with the level of physical activity (PA), expressed as days per week. Percentage of patients revealing a positive self-description is significantly higher when physically active on more than 2 days per week.

\section{Physical Self-Description of Basic Functions of Physical Performance}

Physical self-description of all basic functions of physical performance (strength, endurance, speed, skills, coordination, flexibility) appeared to be related to the level of PA (Figure 2). More physically active patients showed higher percentage of positive self-description of basic functions of physical performance, most consistent for the dimension "endurance."
Further analyzing the physical self-description of the dimension "endurance" (ranging from 6 to 24 points) showed significant reduction in $\mathrm{CHD}$ patients compared to the reference cohort $(p<0.001)$, most noticeable in complex CHD (11.9 \pm 4.9 points) compared to $16.6 \pm 4.5$ points in the reference group (Figure 3). The dimension "endurance" correlated with the level of PA in all CHD groups $(p<0.001)$. 


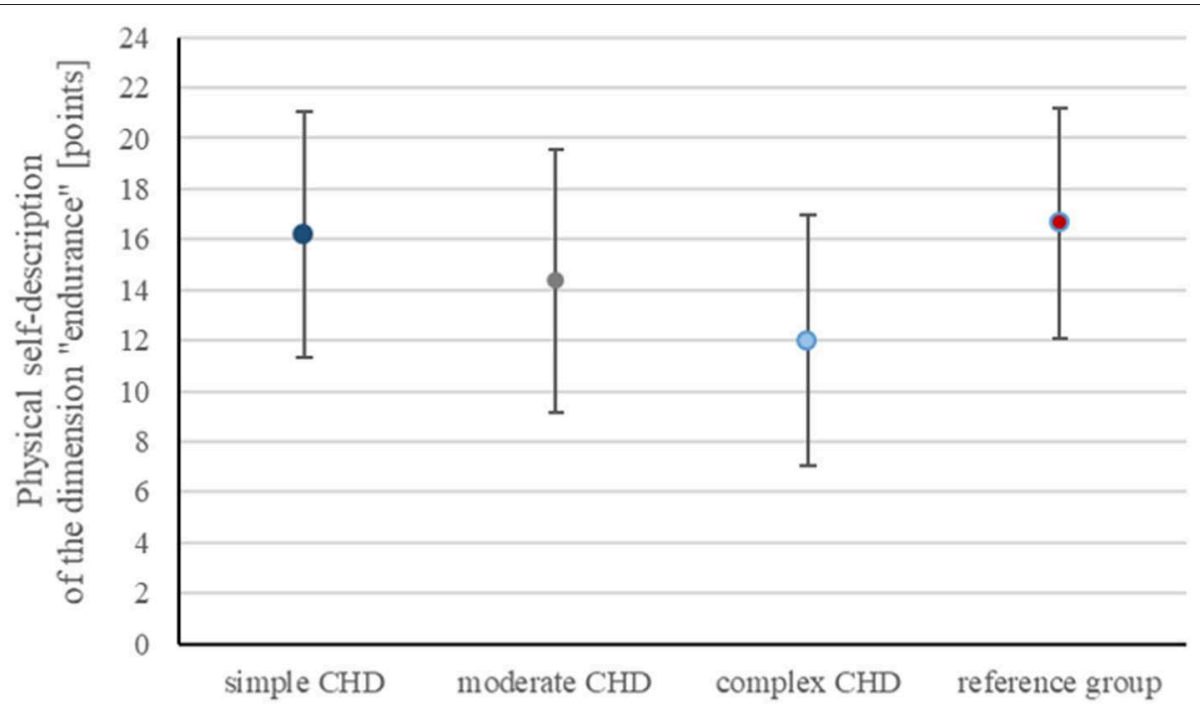

FIGURE 3 | Graphical presentation of physical self-description of the dimension "endurance" (ranging from 6 to 24 points) provided as mean \pm standard deviation showing reduction in CHD patients compared to the control cohort, most noticeable in complex CHD (11.9 \pm 4.9 points) compared to $16.6 \pm 4.5$ points in the reference group.

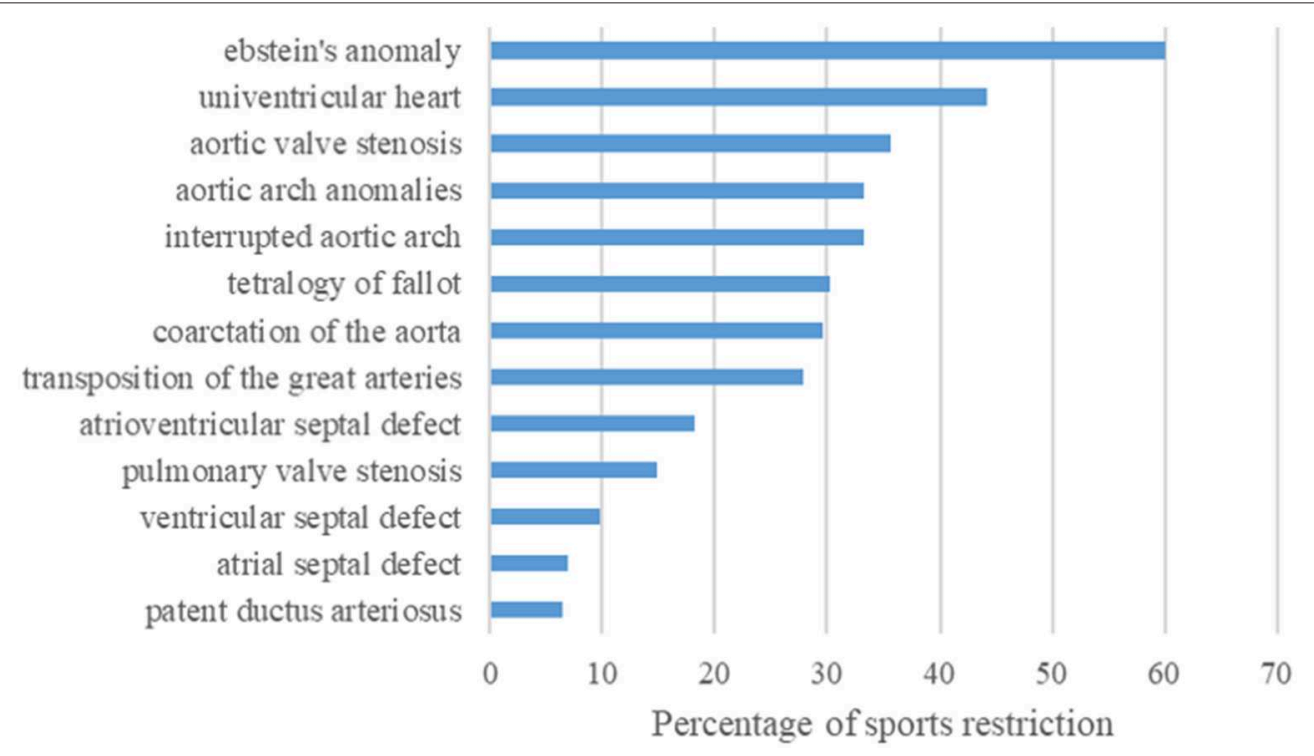

FIGURE 4 | Bar graph showing the frequency of physician-recommended sports restriction in percent dependent on the corresponding CHD diagnosis. Of the 271 of 1.198 children with CHD receiving a sports restriction, most frequent restrictions have been advised in patients with Ebstein's anomaly, followed by single ventricle hemodynamics, and aortic valve stenosis.

\section{Physician-Recommended Sports Restrictions}

$49.2 \%$ of the children with complex CHD, $31.7 \%$ with moderate and even $13.1 \%$ with simple CHD were advised by their physician to restrict PA. 2.3\% of all CHD patients received even a complete dispensation. Most frequently, sports restrictions have been advised in patients with Ebstein's anomaly, followed by single ventricle hemodynamics, and aortic valve stenosis
(Figure 4). Interestingly, also patients with more simple CHD (i.e., ventricular septal defect or atrial septal defect) received sports restrictions. Advisory physicians in terms of sports were predominantly pediatric cardiologists $(55.4 \%)$, followed by pediatricians $(24.9 \%)$, family physicians $(9.2 \%)$, orthopedists (2\%), and sports medicine specialists (1.1\%). In $7.4 \%$ the participant was not aware of the exact professional title of the advisory physician. 
TABLE 2 | Potential factors influencing physical and sports activity.

\begin{tabular}{lcc}
\hline Variable & Regression coefficient & Significance $\boldsymbol{p}$ \\
\hline Age & $-0.077^{\mathrm{a}}$ & $<0.001$ \\
Gender & $0.210^{\mathrm{d}}$ & 0.050 \\
Number of interventions & $-0.056^{\mathrm{b}}$ & 0.005 \\
Residence in rural areas & -0.011 & 0.707 \\
Sports activity father & 0.216 & 0.047 \\
Sports activity mother & 0.017 & 0.571 \\
Enjoyment in sports & $0.103^{\mathrm{c}}$ & $<0.001$ \\
Recommended restrictions & -0.294 & 0.012 \\
\hline
\end{tabular}

${ }^{a}$ Reduction of physical activity per year.

${ }^{b}$ Reduction of physical activity per intervention.

${ }^{c}$ Increase of physical activity per reached point in the PACES scale.

${ }^{d}$ Increase of physical activity of male children.

\section{Factors Influencing the Amount of Physical Activity}

Regression analysis demonstrated a significant impact of age and gender on PA, whereas girls with $\mathrm{CHD}$ demonstrated lower levels of PA. Both, number of interventions and enjoyment in sports play a relevant role on the level of sports activity. Multiple regression analysis revealed physicianrecommended PA restrictions having significant impact on the amount of PA, followed by sports activity of the father, whereas sports activity of the mother and residence in rural areas obviously had no significant impact on patient's PA (Table 2).

\section{DISCUSSION}

To the best of our knowledge, the present study is the largest cohort of children with $\mathrm{CHD}$ that has been investigated for their physical and sports activity behavior. According to this nationwide survey, PA is markedly reduced in children with $\mathrm{CHD}$ living in Germany, and as expected, children with complex CHD showed the most relevant PA reduction. In addition, this study provides information on possible contributing factors that may influence the amount of PA beyond the burden of the heart defect itself, including role model function (regarding sports activity) of the father and an unexpected high rate of physicianrecommended restrictions on PA levels.

Misjudgment in regard of risks vs. benefits of sports participation, as well as overprotection of parents or caregivers, as well as teachers and sport trainers have been previously reported as potential contributing factors $(11,29,30)$. Our results suggest, that also physicians and health care professionals might tend to overprotect, when treating children with $\mathrm{CHD}$, and this obviously often neither in accordance to current recommendations nor supported by scientific evidence, as it has previously been demonstrated that sudden death during exercise is extremely rare in CHD patients (31). Misperception is most notably when considering the relatively high rate of PA restrictions in simple CHD, i.e., patients who usually were allowed to perform unrestrictive leisure and competitive sports.
Recommendations for most patients with CHD include participation in competitive sport, leisure sport and PA unrestricted like healthy children, allowing participation in sports clubs and thus integration in normal social life, except for children with complex CHD or other risk factors (for example pacemaker, cardioverter-defibrillator, channelopathies) who frequently need specific individualized solutions. The latter can be covered by preventive cardiac rehabilitation groups organized by local pediatric heart centers or alternatively by individualized training programs. However, in Germany there are currently only eleven active regional cardiac rehabilitation groups for children with CHD compared to $\sim 6,000$ active cardiac rehabilitation groups for adults (32). Undoubtedly, this availability appears inadequate and is suggested to be influenced by differences in age, gender, interests, severity of CHD and exercise capacity, and additional logistical issues due to living in rural areas with long distances to the regional pediatric heart center. Indeed, our results were able to demonstrate that age, gender, enjoyment in sports and severity of CHD had significant impact on PA levels, however living in rural areas appears not to be a limiting factor, at least in a relatively small country as Germany.

Remarkably, our results show that children with $\mathrm{CHD}$, even with complex CHD had well preserved enjoyment in sports on a similar level as the control group. This has to be considered and implicates that in children the motivation regarding $\mathrm{PA}$ and sports appears to be high, underlining the social implications of sports participation in childhood and supports the feasibility of individual exercise training in the pediatric age group. To maintain or even increase motivation, training programs designed for children should usually prefer varied activity tasks focusing mainly on skills, coordination, and speed, and avoid monotonous endurance training, as frequently used in adults $(11,33)$. The fact that reduced PA correlated with impaired physical self-perception demonstrates the negative psychological consequences of a sedentary lifestyle. This is alarming and might result in a downwards spiral of inactivity. Physicians should therefore regularly advice on patients' PA level and sports activity in every clinical consultation.

\section{Study Limitations}

Data of this survey are based on self- or proxy-reports and might therefore be prone to bias, including recall bias and social desirability, as children with CHD may overestimate their PA level (34). Furthermore, the absence of direct contact with patients may leave the chance for misunderstanding of questions or incorrect answers. To prevent such occurrences each study participant was offered to contact the study management if having any questions. In addition, at the end of the survey there was the possibility to provide ambiguities and questions directly as free text. Clearly, measuring PA by objective methods (i.e., accelerometry, pedometers, activity trackers) might be more precise (14). However, the objective assessment of PA in different domains can be challenging and requires complex strategies, which can hardly be applied in large patient populations. The strength of the current study is the consideration of different 
domains of PA, the large sample size and the inclusion of schoolaged children with a wide age range, as well as the representative reference group.

Since this is a cross-sectional study, we provide descriptive information and report on associations rather than claiming to report causal relationships between $\mathrm{PA}$ reduction and potential contributing factors (2). Moreover, the results reflect respondents' subjective statements. The results may not be applicable to CHD patients outside Germany, since they are affected by the life situation of the patients, as well as the organization of the health care and educational system (2).

Since the patients have been invited by emails to participate in the survey, the response rate of $11.9 \%$ was relatively low. Nevertheless, the sample of patients participating in the online survey did not differ significantly to the entire CHD cohort of NRCHD and therefore seems to be representative for the German CHD community at large.

Theoretically, by considering the prevalence of CHD in the German population of $1.1 \%$, it cannot be ruled out that a minority of participants in the KiGGS study may also be affected by CHD. Due to inaccurate recording of CHD diagnoses in the KiGGS dataset a removal of these participants was not feasible. However, from a statistical point of view, having these children included in the reference group should not result in a relevant bias.

\section{CONCLUSIONS}

According to this nationwide survey, $\mathrm{PA}$ is markedly reduced in children with $\mathrm{CHD}$, at least in part due to an unexpected high number of physician-recommended PA restrictions. As sedentary lifestyle may have negative implications on cardiovascular risk profile and prognosis, future efforts should be directed toward facilitating the access to PA for all CHD patients.

\section{DATA AVAILABILITY STATEMENT}

All datasets generated for this study are included in the article/supplementary material.

\section{REFERENCES}

1. Schwedler G, Lindinger A, Lange PE, Sax U, Olchvary J, Peters B, et al. Frequency and spectrum of congenital heart defects among live births in Germany: a study of the competence network for congenital heart defects. Clin Res Cardiol. (2011) 100:1111-7. doi: 10.1007/s00392-011-0355-7

2. Helm PC, Kaemmerer H, Breithardt G, Sticker EJ, Keuchen R, Neidenbach $\mathrm{R}$, et al. Transition in patients with congenital heart disease in Germany: results of a nationwide patient survey. Front Pediatr. (2017) 5:115.19. doi: 10.3389/fped.2017.00115

3. Pinto NM, Marino BS, Wernovsky G, De Ferranti SD, Walsh AZ, Laronde $\mathrm{M}$, et al. Obesity is a common comorbidity in children with congenital and acquired heart disease. Pediatrics. (2007) 120:e1157-64. doi: 10.1542/peds.2007-0306

4. Tutarel O. Acquired heart conditions in adults with congenital heart disease: a growing problem. Heart. (2014) 100:1317-21. doi: 10.1136/heartjnl-2014-305575

5. Olsen M, Marino B, Kaltman J, Laursen H, Jakobsen L, Mahle W, et al. Myocardial infarction in adults with congenital heart disease.

\section{ETHICS STATEMENT}

The studies involving human participants were reviewed and approved by Ethical Review board of the Charité, Berlin (Approval number 2/034/17). Written informed consent to participate in this study was provided by the participants' legal guardian/next of kin.

\section{AUTHOR CONTRIBUTIONS}

JS, CN, and CA conceptualized and designed the study, drafted the initial manuscript, and reviewed and revised the manuscript. $\mathrm{UB}, \mathrm{HA}-\mathrm{K}, \mathrm{ES}, \mathrm{MU}, \mathrm{MF}$, and AJ designed the data collection instruments, collected data, carried out the initial analyses, and reviewed and revised the manuscript. $\mathrm{PH}$ conceptualized and designed the study, coordinated and supervised data collection, and critically reviewed the manuscript for important intellectual content. All authors approved the final manuscript as submitted and agree to be accountable for all aspects of the work.

\section{FUNDING}

This study was supported by the non-profit organization Fördergemeinschaft Deutsche Kinderherzzentren (grant number W-B-016/2016). The Competence Network for Congenital Heart Defects received funding from the German Federal Ministry of Education and Research, grant number 01GI0601 (until 2014) and the DZHK (German Centre for Cardiovascular Research; as of 2015).

\section{ACKNOWLEDGMENTS}

We thank all the children and their families for participating in this study. We thank Professor Susi Kriemler, Director of Epidemiology, Biostatistics and Prevention Institute, University of Zürich, Switzerland, for the critical review and helpful advice in the preparation of the manuscript.
Am J Cardiol. (2017) 120:2272-77. doi: 10.1016/j.amjcard.2017. 08.050

6. Stefan MA, Hopman WM, Smythe JF. Effect of activity restriction owing to heart disease on obesity. Arch Pediatr Adolesc Med. (2005) 159:477-81. doi: 10.1001/archpedi.159.5.477

7. Dean PN, Gillespie CW, Greene EA, Pearson GD, Robb AS, Berul CI, et al. Sports participation and quality of life in adolescents and young adults with congenital heart disease. Congenit Heart Dis. (2015) 10:169-79. doi: $10.1111 /$ chd.12221

8. Hogan M, Kiefer M, Kubesch S, Collins P, Kilmartin L, Brosnan M. The interactive effects of physical fitness and acute aerobic exercise on electrophysiological coherence and cognitive performance in adolescents. Exp Brain Rec. (2013) 229:85-96. doi: 10.1007/s00221-0133595-0

9. Reybrouck T, Mertens L. Physical performance and physical activity in grownup congenital heart disease. Eur J Cardiovasc Prev Rehabil. (2005) 12:498-502. doi: 10.1097/01.hjr.0000176510.84165.eb

10. Bjarnason-Wehrens B, Dordel S, Schickendantz S, Krumm C, Bott D, Sreeram N, et al. Motor development in children with congenital cardiac 
diseases compared to their healthy peers. Cardiol Young. (2007) 17:487-98. doi: 10.1017/S1047951107001023

11. Takken T, Giardini A, Reybrouck T, Gewillig M, Hövels-Gürich HH, Longmuir PE, et al. Recommendations for physical activity, recreation sport, and exercise training in paediatric patients with congenital heart disease: a report from the exercise, basic \& translational research section of the European Association of Cardiovascular Prevention and Rehabilitation, the European Congenital Heart and Lung Exercise Group, and the Association for European Paediatric Cardiology. Eur J Prev Cardiol. (2012) 19:1034-65. doi: $10.1177 / 1741826711420000$

12. Voss C, Duncombe SL, Dean PH, de Souza AM, Harris KC. Physical activity and sedentary behavior in children with congenital heart disease. J Am Heart Assoc. (2017) 6:e004665. doi: 10.1161/JAHA.116. 004665

13. Arvidsson D, Slinde F, Hulthen L, Sunnegardh J. Physical activity, sports participation and aerobic fitness in children who have undergone surgery for congenital heart defects. Acta Paediatr. (2009) 98:1475-82. doi: $10.1111 / j .1651-2227.2009 .01369 . x$

14. Voss C, Harris KC. Physical activity evaluation in children with congenital heart disease. Heart. (2017) 103:1408-12. doi: 10.1136/heartjnl-2017311340

15. McCrindle BW, Williams RV, Mital S, Clark BJ, Russell JL, Klein G, et al. Physical activity levels in children and adolescents are reduced after the Fontan procedure, independent of exercise capacity, and are associated with lower perceived general health. Arch Dis Child. (2007) 92:509-14. doi: 10.1136/adc.2006.105239

16. Fredriksen PM, Ingjer E, Thaulow E. Physical activity in children and adolescents with congenital heart disease. Aspects of measurements with an activity monitor. Cardiol Young. (2000) 10:98-106. doi: $10.1017 /$ S1047951100006545

17. Massin MM, Hövels-Gürich HH, Gérard P, Seghaye M-C. Physical activity patterns of children after neonatal arterial switch operation. Ann Thorac Surg. (2006) 81:665-70. doi: 10.1016/j.athoracsur.2005. 07.034

18. Ewalt LA, Danduran MJ, Strath SJ, Moerchen V, Swartz AM. Objectively assessed physical activity and sedentary behaviour does not differ between children and adolescents with and without a congenital heart defect: a pilot examination. Cardiol Young. (2012) 22:34-41. doi: 10.1017/S1047951111000837

19. Stone N, Obeid J, Dillenburg R, Milenkovic J, MacDonald MJ, Timmons BW. Objectively measured physical activity levels of young children with congenital heart disease. Cardiol Young. (2015) 25:520-5. doi: 10.1017/S1047951114000298

20. Chen CW, Chen YC, Chen MY, Wang JK, Su WJ, Wang HL. Healthpromoting behavior of adolescents with congenital heart disease. $J$ Adolescent Health. (2007) 41:602-9. doi: 10.1016/j.jadohealth.2007. 06.008

21. Helm PC, Koerten MA, Abdul-Khaliq H, Baumgartner H, Kececioglu D, Bauer UM. Representativeness of the Germany National Register for Congenital Heart Defects: a clinically oriented analysis. Cardiol Young. (2016) 26:921-6. doi: 10.1017/S1047951115001547

22. Jekauc D, Wagner MO, Kahlert D, Woll A. Reliability and Validity of MoMo-Physical-Activity-Questionnaire for Adolescents (MoMoAFB). Diagnostica. (2013) 59:100-1. doi: 10.1026/0012-1924/a0 00083
23. Woll A, Albrecht C, Worth A. Motorik-Module (MoMo) - the KiGGS Wave 2 module to survey motor performance and physical activity. J Health Monitoring. (2017) 2:66-73. doi: 10.17886/RKI-GBE-2017-104

24. Wagner MO, Bös K, Jekauc D, Karger C, Mewes N, Oberger J, et al. Cohort Profile: The Motorik-Modul (MoMo) Longitudinal Study - physical fitness and physical activity as determinants of health development in german children and adolescents. Int J Epidemiol. (2013) 43:1410-16. doi: 10.1093/ije/dyt098

25. Schmidt S, Henn A, Albrecht C, Woll A. Physical activity of German children and adolescents 2003-2012: the MoMo-study. Int J Environ Res Public Health. (2017) 14:1375. doi: 10.3390/ijerph14111375

26. Marsh HW, Redmayne RS. A multidimensional physical self-concept and its relations to multiple components of physical fitness. J Sport Exercise Psychol. (1994) 16:43-55. doi: 10.1123/jsep.16.1.43

27. Jekauc D, Voelkle M, Wagner MO, Mewes N, Woll A. Reliability, validity, and measurement invariance of the German version of the physical activity enjoyment scale. J Pediatr Psychol. (2013) 38:104-15. doi: 10.1093/jpepsy/jss088

28. Warnes CA, Williams RG, Bashore TM, Child JS, Connolly HM, Dearani JA, et al. ACC/AHA 2008 guidelines for the management of adults with congenital heart disease. J Am Coll Cardiol. (2008) 52:e143-263. doi: 10.1016/j.jacc.2008.10.001

29. Longmuir PE, McCrindle BM. Physical activity restrictions for children after the Fontan operation: disagreement between parent, cardiologist, and medical record reports. Am Heart J. (2009) 157:853-9. doi: 10.1016/j.ahj.2009.02.014

30. Ong L, Nolan RP, Irvine J, Kovacs AH. Parental overprotection and heartfocused anxiety in adults with congenital heart disease. Int J Behav Med. (2011) 18:260-7. doi: 10.1007/s12529-010-9112-y

31. Jortveit J, Eskedal L, Hirth A, Fomina T, Døhlen G, Hagemo P, et al. Sudden unexpected death in children with congenital heart defects. Eur Heart J. (2016) 37:621-6. doi: 10.1093/eurheartj/ehv478

32. Siaplaouras J, Albrecht C, Helm P, Sticker E, Apitz C. Physical activity with congenital heart disease: Current options and future developments. Monatsschr Kinderheilkd. (2019) 167:51-7. doi: 10.1007/s00112-0170381-2

33. Zöller D, Siaplaouras J, Apitz A, Bride P, Kaestner M, Latus H, et al Home exercise training in children and adolescents with pulmonary arterial hypertension: a pilot study. Pediatr Cardiol. (2017) 38:191-8. doi: 10.1007/s00246-016-1501-9

34. Rogers R, Reybrouck T, Weymans M, Dumoulin M, Van der Hauwaert L, Gewillig M. Reliability of subjective estimates of exercise capacity after total repair of tetralogy of Fallot. Acta Paediatr. (1994) 83:866-9. doi: 10.1111/j.1651-2227.1994.tb13159.x

Conflict of Interest: The authors declare that the research was conducted in the absence of any commercial or financial relationships that could be construed as a potential conflict of interest.

Copyright (๑ 2020 Siaplaouras, Niessner, Helm, Jahn, Flemming, Urschitz, Sticker, Abdul-Khaliq, Bauer and Apitz. This is an open-access article distributed under the terms of the Creative Commons Attribution License (CC BY). The use, distribution or reproduction in other forums is permitted, provided the original author $(s)$ and the copyright owner(s) are credited and that the original publication in this journal is cited, in accordance with accepted academic practice. No use, distribution or reproduction is permitted which does not comply with these terms. 